\title{
SERVIÇOS DE SAÚDE E POPULAÇÃO DE RUA: CONTRIBUIÇÃO PARA UM DEBATE*.
}

\author{
Nivaldo Carneiro Junior** \\ Edna Aparecida Nogueira** \\ Gisele Magalhães Lanferini** \\ Débora Amed Ali* \\ Marilda Martinelli**
}

\begin{abstract}
RESUMO: O presente estudo tem como objetivo identificar as condiçőes de vida e saúde de uma determinada populaçăo - moradora de rua -, bem como evidenciar sua relaçăo com os serviços de saúde, da perspectiva dos diferentes atores sociais envolvidos. Desse modo, propőe-se fornecer subsidios para as práticas assistenciais de saúde, para a capacitação de recursos humanos e contribuir para a elaboraçåo de políticas públicas especificas. Foram realizadas entrevistas com diferentes atores sociais envolvidos nesta situação: os moradores de rua, os profissionais de saúde, os dirigentes de organizaçőes não-governamentais e as autoridades públicas. A falta de equipamentos sociais e de retaguarda hospitalar, a resistência dos profissionais, as normas vigentes nos serviços de saúde, a desarticulaçăo entre as esferas de governo, tudo isso associado à violência urbana, apresentam-se como expressőes da exclusão social dessa populaçăo.
\end{abstract}

PALAVRAS-CHAVE: população de rua; serviços de saúde; acesso aos serviços de saúde; áreas metropolitanas.

* Apoio Rede de Investigaçáo em Sistemas e Serviços de Saúde no Cone Sul e Centro Intemacional de Investigacão para o Desenvolvimento do Canadá.

* Centro de Saúde-Escola Barra Funda, Departamento de Medicina Social da Faculdade de Ciências Médicas da Santa Casa de São Paulo. Av. Dr. Abrahão Ribeiro, 283 Barra Funda Såo Paulo Capital CEP 01133-020 Fone/Fax: (011) 825.6732. E-mail: csebf@mandic.com.br 


\section{INTRODUÇÃO}

O objetivo deste artigo é apresentar algumas questōes que foram sistematizadas a partir de uma investigação realizada por um serviço de saúde, decorrente da sua experiência cotidiana de assistência à saúde para grupos populacionais em situação de exclusão social, que coabitam a região central do Município de São Paulo, e, no caso especifico deste trabalho, a população adulta de rua.

Este artigo, portanto, traz uma experiência acumulada de uma unidade de saúde, que pretende, desse modo, contribuir para uma discussão acerca da relação entre a população de rua e os serviços prestadores de assistência à saúde.

O Centro de Saúde-Escola Barra Funda (CSEBF), da Faculdade de Ciências Médicas da Santa Casa de São Paulo, localizado numa parte da região central do Municipio de São Paulo há trinta anos, dá atendimento básico de saúde aos que residem e trabalham nos Distritos Administrativos da Barra Funda, Bom Retiro e Santa Cecília. Em anos recentes, extendeu a assistência aos moradores de rua, resultando em transformações no cotidiano das práticas ali desenvolvidas, dadas as novas demandas trazidas por esse grupo populacional, que se desdobraram numa reflexão sobre as possibilidades e as limitaçöes das práticas de saúde frente a essa realidade social (AMED ALI \& DOMINGOS, 1995; CARNEIRO JR. et. al., 1996).

$\mathrm{Na}$ organização dos serviços de saúde, a população de rua ainda não se tem constituído como uma questão de intervenção mais articulada no interior de suas práticas, mesmo nas unidades de saúde localizadas na região central, onde se concentra essa população.

Nesse sentido, os apontamentos aqui levantados podem oferecer subsidios para lançar um olhar mais atento a essa nova realidade que está na "porta" dos serviços de saúde e entidades assistenciais de uma grande metrópole como é o caso da cidade de São Paulo.

A população de rua apresenta-se como um grupo social com dimensões quantitativa e qualitativamente novas na realidade urbana atual. Numericamente, seu crescimento vem se acentuando nos períodos de recessão econômica. Tal expressão tem dado maior visibilidade às suas demandas para diferentes setores da área social, tais como: o da assistência social, da saúde, da habitação e da segurança pública. 
A perda do emprego e as dificuldades da inserção no mercado de trabalho são importantes elementos a justificar a origem desse segmento populacional, seja do ponto de vista da reprodução social, seja pela ética que desprivilegia os que não têm atividade produtiva. Particularmente, esse juizo influencia a dinâmica familiar. Para os chefes de familia, a perda do posto de trabalho é acompanhada, muitas vezes, da perda do status de "provedor", acarretando rupturas nas relaçōes familiares. Portanto, abordagem de ordem sociológica e ideológica devem ser consideradas nesse processo de quebra de laços e deslocamento para a rua (NEVES, 1995).

Essa população fixa-se predominantemente nas áreas centrais das cidades, onde comércio e serviços em geral se concentram, atraindo maior afluxo de pessoas, 0 que possibilita a obtenção de alimentos e alguns recursos financeiros, sendo que, no período noturno, esses locais ficam praticamente despovoados e se transformam em abrigos.

Pesquisa coordenada pela Secretaria Municipal da Família e do Bem-Estar Social da Prefeitura do Município de São Paulo constatou que nas principais regiōes da área central havia cerca de 4 mil moradores de rua. Em sua grande maioria, esta população era constituida, por homens, brancos, entre 30 e 39 anos, oriundos da região sudeste, com primeiro grau incompleto. Ruas e avenidas eram os logradouros mais utilizados para pernoite e os agrupamentos giram em torne de 2 a 5 pessoas com permanência na rua há mais de um ano (VIEIRA et al., 1992).

As informações fornecidas por essa pesquisa têm contribuído significativamente para uma possível caracterização dessa população, diante da inexistência de dados censitários. Um dos aspectos que vem sendo evocado para justificar a não inclusão desse grupo no Censo brasileiro refere-se à dificuldade metodológica de se definir o que se considera população de rua. Nos EUA, por exemplo, os homeless people são aqueles que vivem em condições de precária habitabilidade, não necessariamente os que não têm "teto". No caso do Brasil, a adoção desta definição ampliaria significativamente o número de pessoas a serem incluídas como população de rua.

Alguns autores têm buscado construir uma definição mais apropriada à realidade brasileira, caracterizando-se como população de rua aquelas pessoas que utilizam o espaço público da rua como local de moradia e sobrevivência (VIEIRA et al., 1992; VIEIRA, 1992). Desse modo, essa populaçäo caracteriza-se como grupo heterogêneo, pois "na rua misturam-se trabalhadores, cujas fontes de sobrevivência se originam dela 
própria, como é o caso dos catadores de papel, lavadores e guardadores de carro; outros cujas fontes de sobrevivência não thes permitem o pagamento de moradia, como trabalhadores da construção civil, vigilantes e ajudantes em geral, bem como aqueles que vivem da mendicância e da contravenção, no limite do desinteresse pela atividade socialmente considerada produtiva" (CONDEIXA, 1995:112).

Ainda para esses mesmos autores, considerando-se as razões de se morar na rua, o tempo de permanência na mesma e o grau de vínculos familiares mantidos, a população de rua pode ser classificada em três categorias: ficar na rua (circunstancialmente), estar na rua (recentemente) e ser da rua (permanentemente) (VIEIRA et al., 1992).

Segundo este critério, o "ficar na rua" diz respeito a uma situação recente de desemprego ou de qualquer outro motivo que leva 0 indivíduo a não ter onde morar (migrantes recentes, busca de tratamento médico, dentre outros.). Como a rua intimida esta pessoas, elas vão em busca de albergues ou pensões enquanto possuam algum dinheiro, procurando manter contato familiar freqüente e persistindo, ainda, um projeto de vida.

O "estar na rua" é caracterizado pela permanência mais prolongada na mesma, na qual os pernoites se dão em logradouros e estabelecem-se relações com indivíduos na mesma situação. As pessoas nesta condição consideram-se trabalhadores desempregados, mas ainda mantêm projeto de sair da rua e ao mesmo tempo em que os contatos familiares são menos freqüentes.

A terceira categoria $3 / 4$ ser da rua $3 / 4$ é a que melhor define este grupo populacional, pois a rua passa a ser seu lugar de referência e espaço de relações. Assim, o físico das pessoas submetidas a esta vida se modifica em função de condições limitantes de alimentação e higiene e pelo uso de bebidas alcoólicas e/ou drogas.

Nosso entendimento é o de que esta caracterização possibilita melhor discernimento do problema pois permite instrumentalizar o reconhecimento de necessidades diversas e pode contribuir para a operacionalização de respostas mais adequadas para o estabelecimento de politicas públicas diferenciadas.

A situação precária de vida a que esta população está sujeita, pressupõe um pensar saúde-doença de forma diferenciada, e sendo esse entendimento importante para a formulação de açōes pelos serviços de saúde. A sobrevivência da população de 
rua depende de sua energia física para se locomover, o "trabalho" aparece em forma de ganhos esporádicos, ou nenhuma realização de atividade; a violência urbana quotidianamente vivenciada, a perda de vínculos familiares, entre outros, são fatores de grande importância na concepção do adoecer, no cuidado, e conseqüentemente, no acesso a serviços adequados.

Sabe-se que 0 ato de perceber-se doente é influenciado pela cultura, pelo trabalho e pela renda. O fenômeno de sentir-se doente ou da percepção do próprio corpo por parte dos vários segmentos sociais revela-se desigual, ao referir-se à "leitura" dos sinais de doença. Para os que dependem de seu trabalho para viver, ou até mesmo para sobreviver, os sinais de doença podem ser abafados (BERLINGUER, 1988).

Analisando-se os atendimentos aos moradores de rua, ocorridos em 1996 no Centro de Saúde-Escola Barra Funda (CSEBF), verifica-se que a percepção de estar doente é expressada em situações emergenciais e a concepção de doença é relacionada ao "ficar fraco e não poder trabalhar".

Por outro lado, na assistência à saúde dessa população defronta-se com inúmeras dificuldades, tais como: falta de albergues adequados para a administração de medicamentos controlados; locais para higiene corporal; dificuldades no acesso aos recursos terapêuticos e inabilidade dos profissionais de saúde no trato com este tipo de população. Tais fato, indicam um rol de ineficiência dos serviços de saúde que demandam respostas técnicas, gerenciais e de políticas setoriais, sobretudo as de natureza intersetorial (AMED ALI \& DOMINGOS, 1995; CARNEIRO JR. et. al., 1996).

Diante do exposto, vale destacar parte das questőes apresentadas no projeto de pesquisa: "População de rua: necessidades de saúde e organização de serviços", desenvolvido pelo CSEBF, em conjunto com algumas Organizações Não Governamentais que atuam na região central do Municipio de São Paulo e que recebeu aprovação e financiamento da Rede de Investigação em Sistemas e Serviços de Saúde no Cone Sul e do Centro Internacional de Investigação para o Desenvolvimento de Canadá (IDRC).

Esse projeto objetivou identificar as necessidades de saúde da população de rua, promover articulação entre os diferentes serviços que prestam atendimento a essa população $e$, no futuro, subsidiar a organização tecnológica de assistência à saúde $e$ também promover a capacitação dos profissionais de saúde. 


\section{ASPECTOS METODOLÓGICOS}

Optou-se por uma abordagem metodológica tipo qualitativo, por esta propiciar uma melhor apreensão do "significado" e da "intencionalidade" contidos na problemática a ser investigada, ambos aspectos relevantes para os propósitos desse projeto de investigação (MINAYO, 1992; MINAYO \& SANCHES, 1993).

A estratégia principal de investigação foi a de entrevistar os atores sociais envolvidos direta ou indiretamente com a problemática da população de rua, pressupondose que, através desses relatos, poder-se-ia reconhecer as concepções e atuações desse atores (SCHRAIBER, 1995). Para tal foi utilizado roteiro abertos para realização das entrevistas, que foram gravadas e posteriormente transcritas para serem analisadas.

Este roteiro abrangia as seguintes dimensões: justificativas para estar na rua, principais dificuldades encontradas, modo de vida, concepção sobre saúde e doença, acesso aos serviços de saúde, políticas setoriais e intersetoriais e soluções apontadas. Havia uma parte comum a todos os entrevistados e uma outra adaptada a cada categoria alvo da pesquisa, isto é, moradores de rua, profissionais de saúde, diretores e/ou chefes de seções dos serviços de saúde, gestores da política pública (Secr. da Saúde e Secr. do Bem Estar Social) e representantes de organizações não-governamentais (ONG), totalizando 29 entrevistas.

As entrevistas com os profissionais de saúde, diretores de unidades de saúde, representantes das ONG e dos poderes públicos foram previamente agendadas $e$ realizadas em locais de trabalho. No caso dos moradores de rua, parte deles foi entrevistado nas Casas de Convivências e os demais em logradouros públicos.

Para a análise do acesso aos serviços de saúde pela população estudada, procedeu-se ao levantamento dos atendimentos realizados por alguns dos principais serviços localizados na região central do Município de São Paulo, incluindo o CSEBF.

\section{PRINCIPAIS RESULTADOS}

A população de rua dos moradores de rua pesquisados é constituída por adultos jovens e do sexo masculino. Em grande parte eram procedentes do própria Estado de São Paulo, e encontravam-se há menos de um ano nesta situação $\% / 4$ características 
coincidentes com a pesquisa realizada pela Secretaria Municipal da Familia e do BemEstar Social da Prefeitura do Município de São Paulo citada neste trabalho.

As principais demandas para os serviços de saúde referiam-se aos cuidados de enfermagem, tais como curativos por problemas vasculares em membros inferiores e para outros tipos de ferimentos provocados por agressões físicas; atendimento de serviço social, voltados para pedidos de alojamento e alimentação.

Os principais diagnósticos médicos constatados no atendimento ao grupo pesquisado foram: dependência alcoólica, doenças pulmonares (tuberculose dentre elas) e úlceras e/ou dores nos membros inferiores.

Para melhor ilustrar os enfoques utilizados na pesquisa bem como a sistematização das questões delas decorrentes, apresenta-se a seguir alguns excertos das entrevistas segundo as dimensões estabelecidas no roteiro e as categorias a que pertencem os entrevistados.

\section{- Justificativas para estar na rua}

O desemprego e a perda de papel de "provedor", acarretando rupturas de laços familiares e desintegração do núcleo familiar, são fortes fatores que explicam os motivos para estar na rua, ratificando a discussão sobre os condicionantes sociais e ideológicos desse grupo populacional. Soma-se a esses, os problemas de saúde, tais como, as doenças mentais, o alcoolismo e as drogas, que produzem uma acentuação desse movimento de perdas:

"...Eu fiquei desempregado, eu trabalhava numa firma de segurança..." (morador de rua).

“... Estou na rua porque eu náo arrumo emprego.... Porque minha família é safada, só por isso. É tudo egoísta, é.... Vamos supor, se você tiver com dinheiro, com alguma coisa, se você tiver com dinheiro chegando lá e tudo mais, vocé é bem tratado e tudo mais..." (morador de rua).

“...Há casos que a família rejeita por alcoolismo ou alguma doença que nåo tem como cuidar..." (profissional de saúde).

*...Filho esquizofrénico, aí vocé vai tentar intemaçăo, năo consegue; vai no 
ambulatorio, está lotado.... Ninguém orienta a familia, năo săo todos os lugares que tem um bom serviço de equipe. O que acontece é que a familia se enche e abre a porta, porque eu já ouvi familia dizer isso para mim e năo foi uma so $3 / 4$ vou abrir a porta e vou para cozinha, nê? Năo vi, năo vi; fugiu, fugiu... Eu năo tenho noçăo de número, mas năo devem ser poucos casos..." (profissional de saúde).

"...E decorrente do desemprego e do empobrecimento da populaçăo..." (representante do poder público).

Vale assinalar a organização e produção da assistência médica desigual entre as regiōes do Brasil, faz com que um significativo número de pessoas se deslocam até São Paulo em busca de tratamentos médicos e, parte deles por não disporem de qualquer estrutura de apoio familiar ou de equipamentos públicos que os acolham adequadamente, terminam por ficar na rua e, desse modo, adentrando-se ao "mundo da rua":

"A gente tem visto muitos migrantes que vêm de outras cidades e até de outros Estados, que aparecem aqui na regiăo, por problemas de saúde; eles vem para se tratar em Săo Paulo, ou porque perderam seus empregos e suas familias desintegraram-se, entăo eles acabam nos procurando..." (profissional de saúde).

As justificativas mencionadas acima revelam a complexidade e a heterogeneidade desse grupo populacional. Na rua misturam-se histórias individuais e inserções sociais diversas e, à medida que o "estar na rua" se prolonga, essas diferenças são recolocadas e outras identidades são assumidas.

Essa dimensão é, ao mesmo tempo, reveladora dos limites da intervenção das políticas setoriais, agravada por um quadro de desarticulação e de deficiências de várias naturezas (materiais, recursos humanos, formas organizacionais, entre outros.) encontradas nos equipamentos públicos.

\section{- Viver na rua: seus hábitos e seu modo de vida}

Uma forte caracteristica resultante dessa maneira de vida é a perda da autoestima do morador de rua, visível, por exemplo, no descuido com a higiene pessoal, fator este que rapidamente se instala. Colaboram para acentuar a baixa auto-estima, a falta de equipamentos públicos e violências praticadas entre e/ou contra eles:

“...Briga por motivo comum. Um pega a coisa do outro, o outro vai e revida. Um nåo vai com a cara do outro..." (morador de rua). 
“...Aquele que já está há um bom tempo, mal se reconhece; ...essa violencia toda que ele sofre na rua por tanto tempo, por falta de cuidados, por falta de recursos..." (profissional de saúde).

“...E maltratado por policiais; muitas vezes eles chegam aqui vitimas de agressoes e os policiais falam que acharam daquele jeito, mas a gente sabe que é uma agressấo recente..." (profissional de saúde).

"...Sua auto-estima está muita baixa.... Sua preocupaçăo é só se alimentar..." (profissional de saúde).

“...Nos temos algumas pessoas que aparecem aqui que já foram ex-presidiários, também alguns trabalhadores da construçăo civil, pessoas com algum grau de estudo, pessoas que fizeram vestibular; temos um que fez o curso de Administraçăo, nós temos outros que fizeram, assim, cursos de nível médio e alguns, numa quantidade menor de nivel superior. Nós temos a prostituta de rua, temos o homossexual de nua. Entăo, é uma infinidade, um grupo muito grande de pessoas o qual requer trabalho diferenciado para integraçăo..." (coordenador de ONG).

Sabe-se que esse grupo tem uma dinâmica de vida caracterizada pelo não estabelecimento de quaisquer vínculos com o espaço geográfico específico e com as instituiçőes, tal como ocorre com os andarilhos. Alguns dos entrevistados, expressam certa "liberdade":

“...A pessoa que tá na rua năo pode parar num lugar só, tem que andar pra lá e pra cá, pra lá e pra cá. Tem muito lugar, acaba enjoando daquele lugar de ficar, entăo vai pra outro lugar..." (morador de rua).

“... melhor nome năo seria população de rua, seria populaçăo do mundo. Pessoas que náo têm limites definidos de moradia..." (profissional de saúde).

“...É uma populaçăo fiutuante.... Tem um vínculo diferente com as pessoas, as coisas e os senviços diferentes; muito diferente das outras pessoas..." (gerente de unidade de saúde).

O uso abusivo de bebidas alcoólicas incorpora-se a esse modo de vida, pois é, ao mesmo tempo, forma de aquecimento e embotamento emocional e também atua como fator de aproximação interpessoal: 
-...Quem mora na rua gosta sempre de beber. A única coisa que tá sendo a minha salvaçăo e de vários que dorme na rua. Acho que é tomar pinga, porque ela esquenta, né?..." (morador de rua).

-..A questáo da dependencia alcoblica é complicada de ser tratada nessa populaçăo. A bebida funciona como elemento de socializaçăo entre eles..." (profissional de saúde).

\section{- Estar doente e estar sadio: a concepção}

Segundo os entrevistados, estar doente diz respeito à incapacidade de locomoverse na vida. Tal estado ocasiona impedimento de ir à procura de outros lugares, como por exemplo, das "bocas de rango" (lugares onde se fornece alimentação, organizados principalmente por entidades filantrópicas e religiosas) e portanto de viabilizar a sobrevivência. Salienta-se ser importante essa maneira de perceber 0 agravo, já que conflita com a concepção de adoecimento e de necessidades de cuidados dominantes na sociedade, ou seja, aquela vinculada predominantemente à manutenção da força de trabalho:

“...Năo me dá vontade de andar, quero ficar parado e fico com uma tremedeira, ai eu sinto que to doente..." (morador de rua).

"...É um povo que anda bastante e por isso apresenta problemas vasculares e estáo sujeitos a atropelamentos..." (profissional de saúde).

“...Estar doente é exatamente năo poder ficar em pé..." (coordenador de ONG).

\section{- Acesso aos serviços: organizaçăo e práticas assistenciais}

Este aspecto apresenta diversas questões reveladoras sobre a estruturação, a dinâmica do atendimento, as atitudes dos profissionais de saúde e, de certo modo, a reprodução da exclusão social na atenção à saúde dessa população.

Nesse sentido, é uma dimensão central para os objetivos desse estudo, por se referir a relação entre essa população e os serviços de saúde.

Fortes características do morador de rua, a sujeira e o mau cheiro, são utilizados como justificativas para comportamentos e atitudes de rejeição por parte da sociedade. 
Quanto aos serviços de saúde, estas mesmas características produzem resistências e dificuldades para 0 atendimento desse grupo populacional:

“...Se tivesse um lugar reservado para o morador de rua, o que chegar já encaminha para essa sala, sala especialmente dele... Cada um em seus devidos lugares..." (profissional de saúde).

“..Qualquer clínica que receba uma pessoa nessa situaçăo, eles ligam ao senviço social, porque ninguém quer tratar ou chegar perto..." (profissional de saúde).

"...Existe uma resistência natural, porque é um paciente dificil; ele vem sem tomar banho... enfim, é um paciente dificil de abordar..." (gerente de unidade de saúde).

“...Muitas vezes, as pessoas que vêm aqui tem reclamado dos atendimentos das unidades de saúde. Pelo fato, pelo jeito, pelo cheiro deles..." (coordenador de ONG).

No presente estudo, constatou-se que a população de rua procura os serviços de saúde basicamente para receber cuidados de enfermagem ou para 0 atendimento de demandas que tradicionalmente eles não as tem incorporadas, tais como fornecer banho, alimentação e alojamento. Os Prontos Socorros, de atendimento diuturno, também são procurados devido à falta de acesso a equipamentos sociais mais apropriados às suas necessidades, ou seja, os albergues, na sua maioria, fecham a partir de uma determinada hora da noite, limitando o acesso para pernoites:

“.. Tem uns que vêm só para tomar banho..." (profissional de saúde).

“...Uma grande dificuldade seria mesmo o alojamento, porque nós somos um Pronto Socorro; entåo a finalidade seria um tratamento de emergência e náo um tratamento de casa, comida... certo?..." (profissional de saúde).

"Quando eles vem para dormir, vem após às dezoito horas; eles vem constantemente para dormir... Alguns alegam doença, na realidade săo examinados e nåo tem [doença]..." (profissional de saúde).

A rotina dos serviços de saúde é, em geral, rígida, não levando em consideração as especificidades desses usuários. A burocracia para o agendamento e a exigência de documentos dificultam o acesso dessa população aos serviços. Este tipo de onganização serve, muitas vezes, como explicação para certos comportamentos e atitudes de 
moradores de rua nos serviços de saúde, tais como, as agressões, tumultos e exigências de atendimento imediato. Disto se depreende, a necessidade de se estabelecerem formas adequadas de acolhimento à essa população nos serviços de saúde:

“...Se náo levar uma conta de água, uma conta de luz para eles saberem onde é que a pessoa mora, năo é atendido..." (morador de rua).

"...Eu faço uma briga, ai de repente chega a polícia, a polícia leva eu no hospital e sou atendido..." (morador de rua).

“... O serviço nåo sabe muito bem ainda como lidar [como o morador de rua]; tem um conflito porque a gente nunca sabe estabelecer os limites; é uma populaçåo diferenciada que tem características peculiares, nåo dá para ela entrar direito no senviço como os outros [usuários]..." (gerente de unidade de saúde).

"...Se vocé tiver um local de porta aberta para na hora que ela apareça ser atendida, você consegue alguma coisa. Mas se voce precisar enquadrar essa pessoa nos horários, nos serviços que normalmente funcionam, isto vai realmente representar uma barreira..." (representante do poder público).

Como pode-se observar, também esta situação requer diferentes níveis de complexidade tecnológica na organização da assistência à saúde para se proceda a um cuidado adequado a esta população. Ademais, estas exigências constituem desafios ao Sistema Único de Saúde, pois, muitas vezes, requerem o consenso de ações intersetoriais. Quanto ao atendimento, a população de rua vem sendo tratada como um grande problema para a rede assistencial, ocasionando tensões nas unidades de serviço:

"...A dificuldade da gente é depois da alta, para onde mandar, porque ninguém quer, ninguém aceita. Albergue pð̃e mil empecilhos para aceitar e é só para dormir..." (profissional de saúde).

“... Os abrigos também nåo recebem um paciente que esteja engessado, ou numa convalescência de cirurgia..." (gerente de unidade de saúde).

“...A maioria dos hospitais de retaguarda são privados, com convênio com o SUS e impőem como restriçăo que a pessoa tenha uma vinculaçăo familiar. Aceitam o doente desde que acompanhado da família. Como esse doente năo tem familia, tem dificuldade de ser internado nesses locais..." (gerente de unidade de saúde). 
“...[Há necessidade de ter] Um órgăo que acolha a populaçăo de rua e [promova] um intercâmbio entre Pronto Socorros, as assistentes sociais (...), para conseguir orientá10 [o morador de rua] e que uma vez por mes mande-o aqui, para o nosso ambulatorio..." (profissional de saúde).

“...Esses albergues para pessoas que estăo debilitadas năo săo bons, porque tem que ficar numa fila até sete, oito, nove horas da noite. E eles tem que ficar lá desde nâo sei que horas, para poderem estar mais na frente, para poderem entrar primeiro. Entâo, dá um desgaste muito grande. Outro fator é que eles tem que levantar muito cedo, quatro e meia da manhă, tomar banho frio e sair para rua..." (coordenador de ONG).

*...Eu acho que nenhuma Secretaria Municipal ou Estadual provavelmente vá constituir um senviço especializado para atender a populaçăo de rua. Vocé precisa é ter, em determinadas áreas onde a populaçáo predomine ou circule com mais intensidade, serviços de saúde nos quais voce trate de sensibilizar os profissionais para o problema, até para, eventualmente, ativamente tratarem de captar essa populaçåo..." (representante do poder público).

“...O grande problema dessa gente é a exclusăo social e voce tem dificuldade no serviço de saúde, muitas vezes, de cuidar do cidadâo que tem círculo familiar preparado(...). Agora, quando vocé pega um cidadăo que, de uma certa forma, está excluído, está sem essa possibilidade, entăo o Sistema năo responde certamente para ele..." (representante do poder público).

“...Achamos que há necessidade de um trabalho que envolva outros setores, pois o problema náo é só de responsabilidade de uma Secretaria..." (representante do poder público).

As citações apresentadas sugerem soluções relacionadas à organização tanto do trabalho interno das unidades quanto do trabalho intersetorial.

O levantamento de dados referentes aos atendimentos dos moradores de rua nos diversos serviços de saúde não se mostrou satisfatório, face as dificuldades encontradas para obtê-los, uma vez que as "estatisticas de produçäo" das unidades de saúde não discriminam essa população atendida. 
Essa maneira de registrar os procedimentos reforça a idéia de que a problematização sobre esse tipo de usuário nas unidades de saúde é pouco freqüente.

\section{CONSIDERAÇÕES FINAIS}

A análise do viver na rua, dos equipamentos sociais e de saúde disponiveis indica a necessidade de criação de modelos específicos e açőes adequadas de atenção a esse grupo, em que 0 acolhimento desta classe de usuário torna-se a questão central.

Assim pra os serviços de saúde permanece o desafio de operacionalizar tecnologias voltadas ao atendimento das necessidades desse grupo, e que, integradas a outras demandas, contemplem o conceito de eqüidade.

Vale destacar que diferentes instituiçōes e serviços possuem perspectivas e dimensões próprias de trabalho, ocasionando conflitos e atuações isoladas. Enquanto os serviços de saúde trabalham com a idéia de universalidade, ainda que imersos por uma profunda crise de financiamento, grande parte das ONG tem tradição de lidar com grupos específicos em situação de exclusão social extrema.

Os resultados da pesquisa, apresentados de forma resumida no presente artigo, servem para apontar a necessidade de novos estudos sobre o tema, com o objetivo de produzir uma sinergia de ações entre os niveis envolvidos no acolhimento desses moradores de rua, de modo a configurar um espaço plural nas práticas sociais e de saúde.

Em especial nesse aspecto da construção coletiva das formas de intervenção, este estudo privilegiou os espaços político-institucionais e as reflexões ali produzidas sobre o problema e buscou apontar as possibilidades e os limites das áreas da saúde e da assistência social no acolhimento a esta população.

Vale destacar que o próprio desenvolvimento do estudo ensejou a realização de reuniōes congregando profissionais de saúde de alguns serviços ambulatoriais e hospitalares da área central da cidade e do CSEBF, representantes de algumas ONG com atuação nesta região, técnicos dos órgãos regionais das Secretarias Municipal e Estadual na área da assistência social, nas quais foram discutidos todo o andamento da investigação, através de Fóruns de discussōes, culminando com um grande debate 
ocorrido em outubro de 1997, na Faculdade de Ciências Médicas da Santa Casa de São Paulo, em que foram apresentados os dados desta pesquisa, sua problematização e discutidos os desdobramentos necessários para a melhoria do atendimento a este tipo de demanda social.

Embora se trate de uma iniciativa incipiente e localizada, o desenvolvimento desse estudo e as reuniões por ele desencadeadas, propiciaram contatos e articulações locais entre os serviços, bem como o estímulo para se organizar encontros sistemáticos entre esses parceiros, para o enfretamento da situação vigente na assistência ao morador de rua na região central do Município de São Paulo. Para tanto, criou-se o "Fórum dàs Organizações que Trabalham com a Populaçăo de Rua", que tem-se reunido na Câmara Municipal de São Paulo e vem delineando algumas frentes de luta e produzindo debates, tal como da Lei n. ${ }^{\circ}$ 12.316/97, de autoria da Vereadora Aldaiza Sposati, que estabelece serviços e programas de atenção voltados especialmente ao atendimento da população de rua, ainda que, aguardando regulamentação do Executivo Municipal para entrar em funcionamento.

Por fim, mesmo reconhecendo que o efetivo estabelecimento de uma política articulada entre o poder público e a sociedade civil tem sido a tônica de vários discursos, como a maneira mais eficaz de intervenção nesta situação social, permanece como grande desafio para os diferentes agentes sociais a construção de uma rede de serviços, constituída de instituições públicas e privadas, consubstanciando parcerias efetivas com - Estado, como a resposta assistencial mais adequada à esse grupo populacional.

\section{REFERÊNCIAS BIBLIOGRÁFICAS}

AMED ALI, D. \& DOMINGOS, B. Moradores de rua e o C.S. Barra Funda: a problemática dessa relaçăo e possibilidade deatendimento. Monografia de conclusão de estágio da disciplina Psicologia em Saúde Pública, São Paulo: Pontificia Universidade Católica de São Paulo, 1995.

BERLINGUER, G. A doença. São Paulo: CEBES-HUCITEC, 1988.

CARNEIRO JR. N.; NOGUEIRA, E. A.; LANFERINI, G. M.; MARTINELLI, M.; AMED ALI, D. Populaçâo de Rua: necessidadesde saúde e organizaçăo de serviços. Relatório final de pesquisa. Rede de Investigação em Sistemas e Serviços de Saúde no Cone Sul. São Paulo, 1996 (mimeo.) 
CONDEIXA, D. Ação municipal com a população de rua e as casas de convivência em São Paulo. In: ROSA, C. M. M. (org.) Populaçăo de rua: Brasil e Canadá. São Paulo: HUCITEC, 1995, pp. 61-70.

MINAYO, M. C. S. O desafío do conhecimento: pesquisa qualitativa em saúde. São Paulo: HUCITEC, Rio de Janeiro: ABRASCO, 1992.

MINAYO, M. C. S. \& SANCHES, O. Quantitativo-Qualitativo: oposição ou complementaridade? Cad. Saúde Pública, 9:239-262, 1993.

NEVES, D. P. A miséria em espetáculo. Rev. Serviço Social e Sociedade, 47:79-98, 1995.

SCHRAIBER, L. B. Pesquisa qualitativa em saúde: reflexões metodológicas do relato oral e produção de narrativas em estudo sobre a profissão médica. Rev. Saúde Pública, 29:63-74, 1995.

VIEIRA, M. A. C.; BEZERRA, E. M. R.; ROSA, C. M. M., orgs. Populaçăo de rua: quem é, como vive, como é vista. São Paulo: HUCITEC, 1992.

VIEIRA, M. A. C. A rua como alternativa de moradia e sobrevivência. Travessia, 14:1013, 1992.

\section{HEALTH SERVICE AND HOMELESS PEOPLE: CONTRIBUTION TO A DEBATE}

SUMMARY: This study aims to assess homeless people health and life needs and to establish their relation with health services. By these means, to provide support for health practice, human development and to influence formulation of public policie. Interviewes with different social actors were carried out: homeles people, health professionals, NGO leaders and officials. The lack of social organizations and hospital reference, the professional resistance, the rules of health services and the political disagreements between different levels of government, associated with the urban violence are expressions of the social exclusion that this population.

KEY WORDS: homeless people; health services; health service access; metropolitan area 